\title{
Evaluating the Learning and Development Outcomes of Residence Life Programs - an Australian University Case study
}

\author{
Dr Bradley Kunda \\ Assistant Director \& Residential Life Officer \\ International House \\ University of Sydney \\ Katy Cuthbert \\ Deputy Director, International House \\ University of Sydney \\ Dr Jack Frawley \\ Education Consultant \\ Sydney, NSW
}

\begin{abstract}
University residence halls have long been considered places of student education and personal development, transcending their basic function as a facility merely for living and sleeping. Extensive research over the past few decades shows strong support for residence halls to purposively consider their roles in student development, citing myriad educational benefits for students who live on campus compared with those who commute for their studies. In this context, university professionals have been called on to realise "purposeful, programmatic efforts to integrate students' intellectual and social lives during college" (Terenzini and Pascarella, 1994). Such programmatic efforts in holistic support of a student's life during their tertiary studies have been variously described under the umbrella term "residence life programs".

In this study, we employ a clarificative evaluation methodology to assess the efficacy of a mature residence life program at the University of Sydney's International House. Through the process of program evaluation, we establish the relationship between intentional programmatic efforts on the part of student support staff, and outcomes for student development as evidenced in peer relationships and intercultural learning. Significantly, the findings reveal the real outcomes of structured, informal learning activities on student growth and development, and particularly in the development of cultural competence and peer networks.
\end{abstract}

This evaluative study provides evidence for intangible, and less quantifiable outcomes of residence life programs, which may be used by student life professionals as a basis for further research and program development.

\section{Keywords}

Residence life program, program evaluation, student learning and development, living-learning programs, international students, cross-cultural, informal learning

\section{Introduction}

University residence halls have long been considered places of student education and personal development, transcending their basic function as a facility merely for living and sleeping (Morison, 1936; Pascarella \& Terenzini, 2005; Schroeder \& Mable, 1994). Extensive research over the past few decades shows strong support for residence halls to purposively consider their roles in student development, citing myriad educational benefits for students who live on campus compared with those who commute for their studies (Pascarella, Terenzini, \& Blimling, 1994). In this context, university professionals have been called on to realise "purposeful, programmatic efforts to integrate students' intellectual and social lives during college" (Terenzini \& Pascarella, 1994, p. 32). Such programmatic efforts in holistic support of a student's life during their tertiary studies 
have been variously described under the umbrella term 'residence life programs'.

Using the University of Sydney's International House (IH) as a case study, we employed a clarificative evaluation methodology to establish and assess the relationship between intentional programmatic efforts on the part of student support staff, and outcomes for student development as evidenced in peer relationships and intercultural learning. The findings present insights into the value of structured informal learning opportunities, which may be useful for residence life program managers as they seek to monitor and continually develop their programs along increasingly evidence-based lines. Specific to the present case study, which evaluates a residence life program not yet fully specified or described at the time of commencing the study, the findings reveal how the specific structured informal learning opportunities of regular communal dining can offer real affordances in the development of cross-cultural understanding and intercultural peer networks among university students.

We begin by outlining the context of student development in residence halls, drawing attention to the role played by residence life programs in student development outcomes. We then describe the residence life program at International House before establishing the methodology of our program evaluation, which is clarificative in nature and focusses primarily on three dimensions of the student experience at IH: student satisfaction with their perception of the social climate, student personal growth and development, and student peer relationships. Results from our two modes of data collection are summarised before conclusions are made about the role of residential life programs in supporting the learning and development of higher education students in Australia.

\section{Student development and the role of residence life programs}

Student development theories broadly identify the environmental impact of educational institutions on the holistic growth and development of students. Arthur Chickering's theories remain highly influential here. His "seven key influences" (Chickering \& Reisser, 1993) contain factors that are as applicable to residential environments as they are to other parts of educational institutions. These include the imperative to promote clear and specific institutional directives, as well as to ensure the size of the institution does not become too large that individuals feel 'superfluous'. Chickering stresses the importance of fostering meaningful friendships in diverse student communities, and he encourages student administrators to consider themselves as 'student development professionals' who use programs and services to educate 'the whole student.'

We also know from research conducted since the 1960s that students develop in environments that strike the right balance between challenge and support (Sanford, 1966). Their cognitive complexity is stimulated where they are encouraged to engage in meaningful ways with their college environment (Astin, 1984; Renn \& Reason, 2013). This is important because students during their postsecondary years are often beginning their journey towards self-authorship, negotiating the transition from formulaic dimensions along interpersonal, intrapersonal and cognitive lines towards the more complex process of becoming the 'authors' of their own personal identities (Baxter Magolda \& King, 2012; Kegan, 1982). Noting that interpersonal relationships tend to be the most salient of these formulaic dimensions for traditional-aged university students (Baxter Magolda, 2001), it is meaningful to consider how the social norms established in close-knit residential communities become influential in forming and reforming a student's core identity (Abes, Jones, \& McEwen, 2007). "Residence halls have great potential for fostering development of competence, management of emotions, autonomy and interdependence, and mature interpersonal relationships" (Chickering \& Reisser, 1993, p. 275). In the pursuit of these ends, residence life programs are the structured framework for much of our students' holistic development.

Contributing to this mix of outcomes is the impact of an increasingly diverse student population in Australian higher education institutions today. Overseas students now account for over a quarter of the overall tertiary student population (Australian Government Department of Education and 
Training, 2017), and nearly a third of the overall student cohort at the University of Sydney (The University of Sydney, 2017). It is in this diverse context that International House runs its residence life program, with its explicit focus on the intentional pursuit of intercultural competence. As this study shows, students experience developmental gains in their intercultural competence from both structured activities and informal engagement with their peers.

There are myriad outcomes for students as a result of engagement in residence life programs. Blimling's (2015) recent and extensive literature review of student learning in residence halls revealed eight key outcomes that constitute the greatest influence had on college students through their residential housing experience. These are:

- Academic performance

- Social climate

- Satisfaction

- Retention

- Personal growth and development

- Peer relationships

- Participation in cocurricular activities

- Faculty interaction (Blimling, 2015, p. 122)

In this study, we adopted several of Blimling's outcomes as the basis for an evaluation of the residence life program at International House. We focussed on selected outcomes that are most pertinent to the activities and events that constitute the IH program, identifying specific outputs that can be used to assess the program's effectiveness on facilitating student development.

\section{Case study: The residence life program at International House, the University of Sydney}

The University of Sydney's International House (IH) is home to 200 students representing over 45 nations each semester. It has housed over 6,000 residents throughout its 50-year history, and it continues to support an active alumni membership of over 2,000 former residents from all over the world. IH is a member of the association of International Houses Worldwide, whose common mission - that of fostering international understanding and friendship (International Houses Worldwide, n.d.) - remains a central tenet of the IH mission at the University of Sydney.

From a purely historical perspective, it could be argued that International House was set up as what Blimling would term a "special housing program". Special housing programs "create atmospheres targeted at addressing specific challenges some students face on their campuses" (Blimling, 2015, p. 114). It was a very particular challenge indeed for campus administrators in the 1960 s to provide suitable accommodation for a growing new populace of students from abroad. As the overseas student population at Australian universities has since enjoyed a dramatic increase, the role of International House as a special housing program is arguably no longer as urgent or peculiar as it was in its early decades. On the basis of our evaluation findings, it appears that the house has instead adopted a service provision philosophy more in keeping with the fostering of student development, while retaining its distinctive focus on "fostering international understanding and friendship among residents of International House and members of the wider community" (The University of Sydney International House, 2017).

As a model of purpose-built student accommodation, IH meets the criteria for a "university owned and operated" facility, as distinguished from "private facilities" ("privately owned and operated...not located on a university campus"), "colleges" ("affiliated with a university though operated by an independent organisation that is often religiously affiliated"), and "joint venture 
facilities" ("private developments on university land and university owned facilities that have a management agreement with a private sector firm") (Urbis Pty Ltd, 2018). As a university owned and operated facility, IH is unique at the University of Sydney in that it includes "a mix of fully catered halls with bedrooms and shared amenities off a hallway (and) self-catered apartment style accommodation" (Urbis Pty Ltd, 2018, p. ii).

The residence life program at International House has evolved considerably over the past five decades. For the purposes of the present study, we evaluated the program's specific activities and events as administered since 2015 . We assessed the residence life program holistically as the combined total of all events, products and services that residents engage with during their time at the house. We initially excluded from this definition the physical facilities and material services that are at the core of the house's operational model (for example, the provision of accommodation, catering, and housekeeping), although we kept an open mind about how the program might be clarified to include these types of services based on the evaluation findings.

Consistent with many conventional residence halls, International House's residence life program includes "educational programming planned collaboratively between residents and residence life staff, some form of residence hall government, and student support provided by resident assistants (RAs) and hall directors" (Blimling, 2015, p. 91). The program also adopts elements of what Lenning and Ebbers describe as a 'living-learning community', which includes grouping students together, not only according to their curriculum major or intended career (something not currently done at any University of Sydney accommodation facility) but (relevant to our case study) "in other useful ways, such as multicultural learning communities structured around 'multicultural and interracial themes"” (Lenning \& Ebbers, 1999, p. 42).

By definition, interventionist programs of any nature need to bring about some discernible change in an identifiable audience, usually through the implementation of a set of planned activities (Owen, 2006). To this end, the IH residence life program aims:

- To foster international understanding and friendship among residents of International House and members of the wider community;

- To promote a diverse and inclusive university community where experiences and knowledge are shared;

- To encourage mutual respect and understanding among residents and wider communities; and,

- To develop authentic international perspectives, far-reaching global networks, and lifelong friendships. (The University of Sydney International House, 2017)

In this study, we mapped these institutional aims onto Blimling's broader outcomes of residence life programs to form three categories of evaluation criteria, which are:

1. Student satisfaction with their perception of the social climate;

2. Student personal growth and development; and

3. Student peer relationships.

Through the process of program evaluation, we investigated whether the program's activities in general were achieving International House's stated outcomes. We identified what the program is trying to achieve and made an evaluation as to whether the delivery of the program is consistent with the program plan as evidenced in student development outcomes. We propose that this information will reveal useful insights into the broader effects of residence life programs on the student experience. These insights may have institutional-level implications for student accommodation across the higher education sector. 


\section{Methodology}

The purpose of this evaluation was to assess whether the residence life program at International House achieves its purported aims with respect to student development and the student experience. Our study is grounded in a constructivist theoretical framework which sees knowledge creation as a mutually transactional process between researchers and participants (Denzin \& Lincoln, 2011). How participants make meaning of their experience in the program has been discerned through the methodological approach of narrative inquiry. Narrative inquiry is a way of understanding and inquiring into human experience through "collaboration between researcher and participants, over time, in a place or series of places, and in social interaction with milieus" (Clandinin \& Connelly, 2000, p. 20). Narrative inquiry was considered appropriate here as it reveals the process of inner sensemaking through stories of human (and in our case, the student) experience (Owen, 2006). To evaluate the effectiveness of the residence life program on the student experience, we adopted the research method of program evaluation.

\section{Program evaluation}

Program evaluation is a process of knowledge production (Owen, 2006) that may help us understand the real effects of residence life programs on the student experience. In this case study, we evaluated the residence life program at the University of Sydney's International House against selected criteria relating to the student experience in residence halls. Our overarching research question is:

What effect does the residence life program at International House have on the social climate of the house, the personal growth and development of its residents, and the relationships formed between them?

We adopted a clarificative approach to program evaluation. This approach makes explicit the internal structure and functioning of a program, even while it is still in operation. It is a useful approach to make clear the intended aims and outcomes of a program that may have not been fully specified or described (Owen, 2006). In our evaluation, the relevant value perspectives of the researchers are acknowledged as being in support of the idea that student development denotes the holistic experience of identity formation, which is influenced by a wide range of environmental factors, including specifically the relationships formed with peers and staff members of varying cultural backgrounds while at university. Significantly, residence halls and the purposive programs run within them are valued as influential in the education of the whole person. The fact that residence halls in Australia do not tend to teach formal curriculum does not preclude them from being centres for learning (Parameswaran \& Bowers, 2012).

Our evaluation recognises participants as a social and cultural entity in the sense that they are all members of the University community and are actively engaged in the evaluation process. Key advantages of this approach to evaluation include enhancing the relevance and use of the evaluation data by all partners involved and improving the quality and validity of the evaluation by incorporating the knowledge and experiences of the participants.

This evaluation addresses three criteria:

1. Student satisfaction with their perception of the social climate, focussing on the aims of mutual respect and understanding;

2. Student personal growth and development, which includes an understanding of cultural diversity and current world events, authentic international perspectives, internationalist values, an awareness of safe and respectful behaviour in a multicultural community context, and an awareness of relevant International House and University policies and protocols; and, 
3. Student peer relationships, which includes initial peer networks, international friendships, far-reaching global networks, and life-long friendships.

\section{Data collection and participants}

Two modes of data collection were used in this evaluation: survey data and focus group discussion. Survey data were drawn from existing surveys conducted internally by International House staff since 2016. These surveys evaluated discrete features of the residence life program, including specifically the orientation week and global leadership programs. Also included in this dataset is the annual satisfaction survey completed at the end of each academic year. Participants in these surveys were current residents at the time of data collection, and participant demographic information was not collected as part of these surveys. To the extent, however, that these surveys might be seen as representative of the global population of participants in the residence life program, International House has maintained, for the period pertaining to the collected surveys, a residential cohort numbering 200 residents, with an approximate ratio of 50:50 male- and female-identifying students. Less than $2 \%$ of residents have been neutral or non-gender-identifying. The average student age has been consistently maintained at approximately 21 years. Finally, we include the 2015 alumni impact survey to evaluate the longitudinal impact of the residence life program on peer relationships and long-term personal growth and development. Participants in this survey were residents of International House at some point in its overall period of operation from its first year in 1967 through to 2014, and as such span a very diverse range of age groups.

Complementing these data is a focus group conducted by an independent facilitator to explore a more nuanced and holistic understanding of the resident experience through the personal narratives of four International House residents. All current students in their second consecutive year of residence were invited to participate in the focus group, with a $10 \%$ response rate including students from four continents. The second-year cohort is considered to have met the minimum evaluative criteria of having spent one full academic year in the house, while at the same time being able to draw on the same common set of opportunities offered by the residence life program.

The research team gained ethical approval from the University of Sydney's Human Research Ethics Committee at the outset of the project. This committee approved the logical framework for the study, which specified that data would be collected and used from both focus group discussions and existing surveys, the latter which had been de-identified and aggregated prior to being released to the research team.

Qualitative data from both modes of collection were analysed using a categorical-content approach, incorporating constant comparative analysis (Glaser \& Strauss, 1967; Lieblich, Tuval-Mashiach, \& Zilber, 2011). We aggregated our analysis into responses to the evaluation criteria. The table below shows the relationship between our selected key evaluation criteria, as adapted from Blimling's study (2015), with sub-criteria specific to the International House context, as derived from the house's current strategic plan. Further, we remained open to the possibility of additional themes emerging during the data collection and analysis stages. These are provided in the third column below. The ways in which the IH program meets the proposed sub-criteria will be explored in the discussion section below. 
Table 1 Evaluation Criteria

\begin{tabular}{|c|c|c|}
\hline Key evaluation criteria & Proposed sub-criteria & Emergent themes \\
\hline $\begin{array}{l}\text { Student satisfaction with } \\
\text { their perception of the } \\
\text { social climate }\end{array}$ & $\begin{array}{l}\text { A social climate of mutual respect and } \\
\text { understanding }\end{array}$ & $\begin{array}{l}\text { Student expectations about making } \\
\text { friends } \\
\text { The formation of groups } \\
\text { Social challenges }\end{array}$ \\
\hline $\begin{array}{l}\text { Student personal growth } \\
\text { and development }\end{array}$ & $\begin{array}{l}\text { Understanding of cultural diversity and } \\
\text { current world events } \\
\text { Authentic international perspectives } \\
\text { Internationalist values }\end{array}$ & $\begin{array}{l}\text { Informal learning experiences } \\
\text { Formal learning experiences }\end{array}$ \\
\hline Peer relationships & $\begin{array}{l}\text { Initial peer networks } \\
\text { International friendships } \\
\text { Far-reaching global networks and life- } \\
\text { long friendships }\end{array}$ & (No further themes emerged) \\
\hline
\end{tabular}

\section{Procedures for data analysis}

Both qualitative survey responses and focus group data were coded using a method of constant comparative analysis. The research team divided existing surveys and the focus group transcript into relatively equal sections and commenced coding in accordance with the three key evaluation criteria identified above. Prior to coding, the research team jointly analysed a randomly chosen passage from the focus group transcript to assess for inter-coder reliability, which was established following a discussion of the key concepts relating to the criteria as defined by Blimling.

\section{Limitations}

The major limitation of this study is the small sample size of the focus group, and the fact that only one focus group was conducted. Timing of the data collection, as well as the short timeline for the overall evaluation project, may have been contributory factors here. The timing of the study in particular may impact the reliability of the results, particularly as it coincided with policy changes that were external to International House but which have had a significant effect on the community, for example the Broderick report (Broderick \& Co, 2017). Moreover, data collected from residents can only illuminate the experiences of their own cohort, and conclusions drawn from one group may not necessarily accurately reflect experience of residents from previous years. We caution the over-reliance on student satisfaction in our discussion section below. As our findings reveal the dynamic nature of the social climate in residential communities, it would be beneficial to collect further data by extending this project into a longitudinal study.

Further, there exists the possibility of false-consensus bias arising from the use of focus group discussions. Our use of existing psychological literature relevant to student development may go some way to ameliorating any effects of false-consensus bias, however it is recommended that further data collection might also include one-to-one interviews with students to better allow for the expression of honest personal opinions. Despite the relatively small sample size of our focus group, it is worth noting that the group itself did represent a diverse cross-section of the overall residential cohort, and that the cultural diversity within the focus group allowed for representation of major demographic units within the IH community. Focus group data thus add valuable qualitative richness to the materially more substantial survey data.

Bearing these limitations in mind, this research paper is offered as a preliminary study that shows the applicability of a clarificative program evaluation method in researching the social impacts and learning and development outcomes of residence life programs on tertiary students in Australian universities. The findings suggest there is value in qualitatively evaluating the student learning experience of residence life programs, beyond solely relying on reports of student satisfaction. 


\section{Data-sets used}

- Resident satisfaction survey $(2016,2017)$

- Arrival and orientation survey $(2016,2017,2018)$

- Global leadership program survey (2018)

- Alumni impact survey (2015)

\section{Analysis of results}

\section{Student satisfaction with their perception of social climate}

One of the greatest expectations, and also the greatest pre-arrival concern for students, was the prospect of making friends. This was nominated as the most significant issue in the five orientation and arrival surveys. Students viewed the opportunity to live at IH as a way of differentiating their university residential experience from their pre-Sydney experience. They wanted to make friends, and they expected the social climate to be welcoming and homely:

I wanted to be in an environment that was easy to make friends with, not live in an apartment alone. (Focus group participant)

I am from China and basically my reason for choosing here is...because here is like a community and I can meet friends. Basically, my best friends in Australia are here. I want to know more about Australia. (Focus group participant)

When commenting on the social climate of International House, there was a degree of apprehension felt by some in their initial experiences of settling in. One felt "a bit out of place at first" and another a degree of loneliness. Despite these challenges and misgivings, a number of enablers assisted students to make the transition into the residential community. The welcoming attitude of staff and current residents was viewed in the surveys as the most crucial factor in assisting new arrivals to adjust to the social climate of International House. Orientation week was also identified as important in assisting students to be "fully immersed in the whole thing", with the support of "older residents who are helping (new arrivals) through the o-week activities" (Focus group participant). Participants also described how dining hall interactions enable regular engagement with peer social groups, with positive flow-on effects for personal support:

It's more on a daily (basis); it's more sitting down and talking with someone in the dining (hall).

(Focus group participant)

So, for me it's all about the dining hall, the majority of my social life. (Focus group participant)

Students commenced forming peer friendships very early in their residency, after which they began to form smaller groups. The formation of groups was discussed by several focus group participants with a degree of ambivalence, and it became clear that the formation of groups does not appear to align with resident expectations of a diverse and welcoming community. This is illustrated in one participant's concern about a "divide" in the dining hall between where Asian and non-Asian residents sit to eat. One participant cited how language barriers contributed to this divide, observing how the fast rate of spoken English made it difficult for native Chinese speakers to "catch up". The same participant also acknowledged the tendency for people to stay in their "comfortable zone", reluctant to involve non-group members once the group is formed.

Despite these challenges, an overwhelming majority of residents consistently reported in annual satisfaction surveys an extremely high level of satisfaction with the social climate at IH. More than $90 \%$ of respondents consistently reported feeling a 'sense of belonging' at $\mathrm{IH}$, while also stating 
they would be willing to recommend $\mathrm{IH}$ to a friend. The strong sense of belonging, the clear formation of friendship groups, and the positive effects of the orientation program speak to the successes of the house in promoting an inclusive community.

\section{Student personal growth and development}

Some residents felt at a personal level that the opportunity to be exposed to authentic international perspectives was rewarding for their own development: "I think that's something uniquely valuable about International House: that everyone's from somewhere a bit different and has different things to say" (Focus group participant). Respondents to the 2015 alumni impact survey strongly supported this claim, 88\% citing that living at IH influenced their worldview and expanded their thinking: "It broadened my mind and my heart"; "It made me a more expansive, outward-looking thinker"; "I gained a worldly perspective that affects my decision making". Many alumni reported experiencing a profound change, citing $\mathrm{IH}$ as the reason for a radical shift in their development: "A paradigm was broken"; "It changed my personality".

It does seem that alumni respondents reported a stronger association than that expressed by residents between their experience at IH and the development of their international understanding. Indeed, an emergent theme in the resident focus group discussion was ambivalence about the causal link between international understanding and current IH events:

I don't know about international understanding, like the understanding bit. I was going to say celebrating a diverse culture. (Focus group participant)

Of the 80 events or whatever I don't think any of them have much to do with international understanding. (Focus group participant)

I certainly think on the whole the events International House runs probably expose (us) more to international understanding than if I was to be somewhere else for sure, but I don't think many events really do. I think it's more just the (daily) communications you have with people. (Focus group participant)

At the same time however, residents expressed divergent views about what might actually constitute international understanding, citing regular and informal engagement with peers as contributing more to developing international understanding than formal events: "I think it's just being friends with (others), you just learn that way more often than not" (Focus group participant). Resident participants consistently cited regular meals in the dining hall as being of vital importance in their development of international understanding:

For me, I think like they said, having breakfast together, having lunch and dinner all together and sitting with people, talking about your country. Sometimes I find a news item in maybe Bangladesh and then I'm like okay, I want to know more about this, why are people protesting about this, and I'll find someone from Bangladesh because it's a great opportunity having someone in International House who is directly from there, you can get to know if the issue had a cultural root the person could explain far better than sometimes reading news items randomly online. (Focus group participant)

I think international understanding, for me it's about having breakfast, lunch and dinner together. (Focus group participant)

The dining hall was reported as the most frequently used common space by residents of the house. ${ }^{1}$ The daily sharing of meals therefore seems to play a significant role in how students participate in the residential life of the house, providing opportunities not only for peer engagement but also

12017 Satisfaction Survey $=75.76 \% ; 2016$ Satisfaction Survey $=44.16 \%$ 
informal peer learning, with perhaps a natural orientation towards international understanding owing to the culturally diverse composition of the residential cohort. Significantly, the causal link between dining hall interactions and international understanding finds support in the responses of alumni to their time in the house, where social interactions were identified as enabling the formation of international perspectives and values:

Chatting with friends from all over the world over meals and social activities has broken stereotypes and broadened my world view. (Alumni impact survey respondent)

The cultural melting pot at meal times gave me meaningful insights into some truly great people. (Alumni impact survey respondent)

\section{Peer relationships}

Both current residents and alumni highlighted their peer relationships as the most pertinent and enduring feature of their residential experience at $\mathrm{IH}$.

While strong friendships were seen to form from very early on during residency, students nevertheless identified ambivalent feelings about their initial perceptions of forming peer networks. These included dealing with different personalities of other residents, "Not weird in the sense of diversity but personality types, the way people talked to you." Participants also mentioned what they felt was a problem with group formation in that groups were closed and not open to other membership:

Sometimes if you try to join another table it feels like you're the odd person among them and sometimes communication ceases, and sometimes you see these Asian tables and if you try to sit in on it, it looks like kind of weird person - you know? (Focus group participant)

Despite these challenges students commenced forming peer networks very early in their residency based on welcoming attitudes that were inclusive: 'Our first semester everyone was like a big family, I didn't need to pick a table, I could sit anywhere', which 'didn't feel like it was cliquey' and led to International House 'feeling like home because a lot of people be talking to you' (Focus group participant).

These relationships were often formed across cultures, allowing for different perspectives to be considered:

\section{It's exposed me to a whole bunch of new perspectives on things. (Focus group participant)}

Alumni respondents confirmed the emphasis placed by current residents on the value of peer relationships formed within the house. Respondents to the alumni impact survey answered more favourably to whether they maintained contact with their IH peers than to whether house relationships became professional contacts, with $70 \%$ claiming to maintain contact with fellow residents, and a further $23 \%$ maintaining intermittent contact. Only $7 \%$ indicated that they no longer maintain contact with their International House peers.

Alumni respondents were also more inclined than current residents to adopt strongly emotive language to describe their experience of making friends at the house, with many references to their enduring (life-long) quality:

I had the best time of my life while staying at International House. I gained an enormous amount of confidence and made excellent friends. (Alumni impact survey respondent) 


\section{Discussion}

\section{Perception of social climate}

The concern with making friends and forming groups is a typical and anticipated experience for residential hall students. According to Blimling, group approval and connection with a group in late adolescence is important because of the "psychosocial need to define identity". For most postsecondary students, decision-making is still dependent on group validation. As students then mature, decision-making becomes reliant on an individual's own ethics, values and sense of identity (Blimling, 2015, p. 73). It is therefore anticipated that students in residence halls, like most university students, will be anxious about making friends and forming groups.

As IH residents began forming groups and bonding through shared events and experiences, their groups started to exert significant emotional influence over them. For certain residents, group formation made IH feel "like home". Their misgivings about being "comfortable" within their own groups (to the exclusion of participating in other groups) intimate the next stage of student development: that $\mathrm{IH}$ residents are beginning to expect more from themselves and their experience. It may be possible that the student-proposed solutions to the dining hall 'divide', which include more formal program events throughout the semester, could facilitate our students in bridging interrelational gaps between groups. ${ }^{2}$

Our focus group participants did not conform to Blimling's suggestion that students tend to favour their own groups over others. Blimling says "once individuals identify with a group, they come to prefer that association and often disparage other groups". Rather, the highly empathetic discussion around the dining hall 'divide', where focus group participants expressed a genuine understanding of the experience of other groups and the primary reasons behind the 'divide' (i.e. language barriers), would suggest that $\mathrm{IH}$ is succeeding in its mission to create a social climate of respect and understanding.

\section{Student personal growth and development}

While a discussion of the impact of formal learning opportunities at International House lies beyond the scope of this paper, one of the salient findings of the evaluation reveals the ways in which informal peer engagement enables the development of international understanding. Allowing for the benefit of retrospective sensemaking afforded by many of our alumni respondents, the impact of daily interactions across cultures was often acknowledged as profound. As for our current residents, the way they access knowledge about the other through regular conversations in the dining hall is a strong indicator that the international perspectives they are gaining are properly authentic.

The fact that informal learning appears to take priority over formal activities for our respondents is consistent with research on student development in residence halls (Blimling, 2015). The dining hall was consistently cited by both residents and alumni as a locus of learning and development at International House. This finding too is consistent with research into the ways students learn in residence halls. It bears noting, however, that informal learning does not equate to accidental learning: Blimling reminds us that "The intermediate peer environment (of residence halls) is structured to create conditions that engage students in active learning. It is through social interactions in this environment that students learn" (Blimling, 2015, p. 59). IH resident and alumni respondents alike confirmed the inherent value of the structure that is daily meals together in the dining hall. We might also extend the program's structure for informal learning to the house's selective admissions process, which is designed to maximise the diversity of the residential cohort. It is thus with a view to clarifying the nature of the residence life program that structures for informal

\footnotetext{
2 For example, one focus group participant suggested including in the program an event 'once a week...to have something going on consistently that would encourage people to go along to dinner on that night...that would encourage the communal vibe a bit more.'
} 
learning, especially the house's full catering service in a dedicated dining environment, be included as vital aspects of the program, particularly for their proven value in facilitating an understanding of cultural diversity and the development of international perspectives.

To the extent that residents are developing internationalist values, it bears noting that a specific list of 'internationalist values' does not appear in the International House strategic plan, ${ }^{3}$ and so it is difficult to assess what values the IH program purports to develop in its residents without a further investigation of the subject of internationalism, which lies beyond the scope of this evaluation. Nevertheless, students did give evidence of emerging ethical development (Perry, 1968) in the form of a commitment to community values and participation. One survey respondent highlighted this nicely by acknowledging that, despite feeling limited by a perceived language barrier, their participation in the academic support program enabled them to feel that they "really can contribute something to the community". A focus group participant in a leadership role reflected that "(I) really enjoyed it because you actually get the chance to help someone. I think that's the reason I wanted to do it was to make IH more of a better place to live". Viewed in light of relevant student development literature, this commitment to community participation for the benefit of others signals a move to the higher order of ethical development, which usually follows only after sufficient cognitive development has been attained (Perry, 1968).

\section{Peer relationships}

There was considerable overlap between responses that addressed the criteria of peer relationships on the one hand, and satisfaction with the perception of social climate on the other. Initial peer relationships were often seen as confronting, with residents identifying challenges arising from the diversity of personality types, along with some communication issues. The orientation week surveys indicated overall satisfaction with IH events in that they provide residents with the opportunity to meet a diverse range of people. After attending events early in the semester, friendships and support circles begin to form.

There is considerable evidence that International House successfully enables the formation of friendships, which often go on to become life-long friendships. Alumni respondents attested to how their International House experience was a key moment in their lives, and that the people whom they met then continue to be significant in their lives.

While there is evidence from both the focus group and alumni that friendships were formed between cultural groups - "from all continents" - the dining room divide indicates that the diversity and inclusivity of friendship groups could nevertheless be improved. The divide in the dining hall was attributed to language barriers. Elements such as speech rate and use of colloquialisms, combined with some residents then choosing to speak in languages other than English, may be constraining the formation of international friendships. All University of Sydney students have very competent English skills, but this does not mean they have native fluency. Further research and program development addressing the influence of language on cultural competence could be useful in ameliorating the dining hall divide.

There is evidence that peer relationships formed at IH do go on to become far-reaching networks, with emphasis placed by alumni on friendships being sustained in a purely personal, rather than professional context.

\section{Conclusions}

Overall, this study suggests that the International House residence life program appears to be achieving its intended purpose of supporting students to develop international understanding and

\footnotetext{
3 Institutional values of 'diversity and inclusion'; 'understanding and empathy'; 'respect'; 'engagement'; 'integrity'; and 'excellence' are included in the house's Strategic Plan 2017-2020, however it is unclear whether all of these values might de facto amount to 'internationalist' values.
} 
authentic international perspectives. Residents appear to experience developmental gains in their cultural competence through informal interaction with their peers. Regular meals in the dining hall were consistently cited as the key enabler for the formation of authentic international perspectives and friendships.

Friendships formed at IH have been shown to be of valuable personal support, and are in most cases long enduring and even life-long. Students form closed friendship groups in ways that are consistent with their stage of personal development, however IH residents also show a more mature sense of empathy, respect, and understanding of the differences that separate their own groups from others. This sense of understanding further attests to the success of the IH program in achieving the house's specific aims of fostering a social climate of mutual respect and understanding. Where differences between social groups have been identified, these are largely located in the context of the dining hall. While being considered as a locus of social activity at the house, the dining hall is also the site of persistent division between key cultural groups. Language barriers seem to be the root cause of group differentiation in the dining hall.

The 'dining hall divide' will likely remain in place unless interventionist strategies are implemented to address existing language barriers. Further opportunities for research and program development include exploring educational opportunities for native English speakers and speakers of English as a second language that focus on discerning how language barriers may affect social inclusion. The influence of language on cultural competence could also be investigated as a potential area for further research, the findings of which might be useful in enhancing the social impact and learning and development outcomes of the residence life program.

Further, when comparing alumni and resident data, particularly around the impact of peer relationships and the effects of living and learning within a culturally diverse community, limitations for program evaluation emerged from overreliance on the perceptions of current students. As we see in this study, student expectations of how their relationships ought to form, for example, do not necessarily align with reality, something that is evidenced by research in student development and psychology. This has broader implications for how we use student feedback, which the authors suggest should be read in the context of student development theories, and ideally compared to more longitudinal data for greater accuracy.

At the outset of this evaluation project, the research team defined the IH program holistically as encompassing all the events, products and services that residents can access during their time in the house. In clarifying the scope of the IH program, it would be remiss not to single-out, as a key component of the program, the vital role played by the structured routine of daily meals in the dining hall. Based on the results of this study, we now know the importance of this daily interaction in enabling the development of authentic international perspectives and the formation of invaluable peer networks. Residents and alumni see the dining hall as a critical factor in the social climate of the house, and they are sensitive to ways in which people form groups together within the dining hall. The impact of the dining hall on student peer relationships and intercultural learning is vital evidence of the success in which IH is achieving its institutional aims.

Considered more broadly, this study provides a framework for qualitatively evaluating tertiary residence life programs with a focus on student learning and development outcomes. This is particularly useful in the Australian context, where most if not all student accommodation facilities run programs independent of formal tertiary curricula offered by higher education institutions. Noting that this study is only preliminary in nature, the findings themselves nevertheless suggest the possibility of educational value in structured informal learning experiences, included among which is the daily routine of communal dining. Further studies of a wider scope investigating the specific impact of structured informal learning experiences, might also make use of pre-arrival and post-departure data collection. Of additional benefit could be comparative studies evaluating 
programs across distinct groups of self-catered and catered residents. We welcome further formal evaluative study into the learning and development outcomes of Australian tertiary residence life programs to expand upon these findings. 


\section{References}

Abes, E. S., Jones, S. R., \& McEwen, M. K. (2007). Reconceptualizing the model of multiple dimensions of identity: the role of meaning-making capacity in the construction of multiple identities. Journal of College Student Development, 48(1), 1-22.

Astin, A. (1984). Student involvement: a developmental theory for higher education. Journal of College Student Personnel, 25, 297-308.

Australian Government Department of Education and Training. (2017). Higher education student enrolment summary statistics for the 2016 full year. Retrieved from https://docs.education.gov.au/node/45141

Baxter Magolda, M. B. (2001). Making their own way: Narratives for transforming higher education to promote selfdevelopment. Sterling, VA: Stylus.

Baxter Magolda, M. B., \& King, P. M. (2012). Assessing meaning making and self-authorship: theory, research, and application (Vol. 38). San Francisco, CA: Jossey-Bass.

Blimling, G. (2015). Student learning in college residence halls: What works, what doesn't, and why. San Francisco, CA: Jossey-Bass.

Broderick \& Co, E. (2017). Cultural renewal at the University of Sydney residential colleges. In. Sydney, NSW: Elizabeth Broderick \& Co.

Chickering, A., \& Reisser, L. (1993). Education and identity. San Francisco, CA: Jossey-Bass.

Clandinin, D. J., \& Connelly, F. M. (2000). Narrative inquiry: Experience and story in qualitative research. San Francisco, CA: Jossey-Bass.

Denzin, N. K., \& Lincoln, Y. S. (Eds.). (2011). The SAGE handbook of qualitative research (4th ed.). Thousand Oaks, CA: Sage Publications.

Glaser, B. G., \& Strauss, A. L. (1967). The discovery of grounded theory. London, UK: Weidenfeld and Nicolson.

International Houses Worldwide. (n.d.). IHWW Official Website. Retrieved from http://ihouseworldwide.org/

Kegan, R. (1982). The evolving self: Problem and process in human development. Harvard, MA: Harvard University Press.

Lenning, O. T., \& Ebbers, L. H. (1999). The powerful potential of learning communities: Improving education for the future (Vol. 6): Association for the study of higher education; ERIC Clearinghouse on higher education, Washington, DC; George Washington University, Washington, DC Graduate School of Education and Human Development.

Lieblich, A., Tuval-Mashiach, R., \& Zilber, T. (2011). Narrative research. Thousand Oaks, CA: Sage Publications.

Morison, S. E. (1936). Harvard College in the seventeenth century. Cambridge, Mass.: Harvard University Press.

Owen, J. M. (2006). Program evaluation: Forms and approaches. Sydney, Australia: Allen \& Unwin.

Parameswaran, A., \& Bowers, J. (2012). Student residences: From housing to education. Journal of Further and Higher Education, 38(1), 57-74.

Pascarella, E., \& Terenzini, P. (2005). How college affects students: Volume 2: A third decade of research. San Francisco, CA: Jossey-Bass.

Pascarella, E., Terenzini, P., \& Blimling, G. (1994). The impact of residential life on students. In C. C. Schroeder (Ed.), Realizing the educational potential of residence halls. San Francisco, CA: Jossey-Bass.

Perry, W. G. J. (1968). Forms of intellectual and ethical development in the college years: A scheme. New York, NY: Holt, Rinehart, \& Winston.

Renn, K. A., \& Reason, R. D. (2013). College students in the United States: Characteristics, experiences, and outcomes. San Francisco, CA: Jossey-Bass.

Sanford, N. (1966). Self and society. New York, NY: Atherton Press.

Schroeder, C. C., \& Mable, P. (1994). Realizing the educational potential of residence halls. San Francisco, CA: JosseyBass.

Terenzini, P., \& Pascarella, E. (1994). Living with myths: undergraduate education in America. Change, 26(1), 28-32.

The University of Sydney. (2017). Annual report. In. Sydney, NSW. 
The University of Sydney International House. (2017). International House strategic plan 2017-2020. In. Sydney: The University of Sydney.

Urbis Pty Ltd. (2018). Regional student accommodation assessment. Retrieved from https://apo.org.au/sites/default/files/resource-files/2018/04/apo-nid142551-1217476.pdf

The authors may be contacted via

bradley.kunda@sydney.edu.au

Please cite this paper as:

Kunda, B., Cuthbert, C. \& Frawley, J. (2020). Evaluating the learning and development outcomes of residence life programs - an Australian university case study. Journal of the Australian and New Zealand Student Services Association, 28(1), 5-20. https:// doi.org.10.30688/janzssa.2020.04 